\title{
Sustainable organisational learning in sustainable companies
}

\author{
Cinzia Battistella \\ Polytechnic Department of Engineering and Architecture, University of Udine, \\ Udine, Italy \\ Lucia Cicero \\ Department of Asian and North African Studies, Ca' Foscari University of Venice, \\ Venice, Italy, and \\ Nadia Preghenella \\ Department of Management and Engineering, University of Padua, Vicenza, Italy
}

Received 16 May 2019

Revised 14 October 2019

8 May 2020

29 June 2020

10 September 2020

\begin{abstract}
Purpose - The purpose of this study is to extend the knowledge on sustainable organisational learning (OL) in sustainable companies.

Design/methodology/approach - Sustainability is examined from an OL perspective and was based on Edward's integral cycle of learning. An in-depth analysis of the literature was carried out, and a list of OL characteristics, such as openness to new ideas and participative policymaking, were compiled. To identify which OL characteristics are used for sustainability, a multiple-case study was designed for sustainable companies operating in the food and beverage industry.

Findings - This study found a wide variety of sustainable practices, such as experimentation and information-sharing systems, related to learning processes, and learning leadership appears to be the least developed dimension. It was also found that sustainable companies learn through social rather than reflective learning, in relationships with internal and external stakeholders, and by concrete actions to implement environmental and social impacts.
\end{abstract}

Originality/value - This study is one of a few that explore sustainable OL and contributes to categorising OL characteristics that sustainable companies use to facilitate and support sustainability in the mid-long term.

Keywords Organisational learning, Sustainability, Case study, Experiential learning, Learning orientation, Learning process, Stakeholders' engagement, Leadership

Paper type Research paper

\section{Introduction}

Over the past few years, companies have become more committed to sustainability-related activities. They have sought to include several sustainability features in their strategy and decision-making processes with the aim of gaining a competitive advantage (Johnson and Schaltegger, 2016; Jansson et al., 2017; Ritala et al., 2018).

However, to incorporate sustainability features in a company's business model a business learning process (Jamali, 2006) that involves the identification of learning dimensions applied to

(C) Cinzia Battistella, Lucia Cicero and Nadia Preghenella. Published by Emerald Publishing Limited. This article is published under the Creative Commons Attribution (CC BY 4.0) licence. Anyone may reproduce, distribute, translate and create derivative works of this article (for both commercial and non-commercial purposes), subject to full attribution to the original publication and authors. The full terms of this licence may be seen at http://creativecommons.org/licences/by/4.0/legalcode

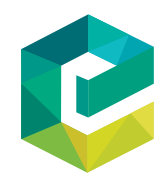

The Learning Organization Vol. 28 No. 1, 2021 pp. $15-31$ 
TLO

28,1

environmental and social issues is necessary. A management orientation supporting continual adaptability and learning, leads to a better linkage among the three pillars (i.e. economic, environmental and social) of sustainability (Jamali, 2006). Such an orientation should seek to improve not only economic benefits like income generation but also to satisfy sustainability needs through a continuous learning approach to strategy.

Despite the acknowledgement of the will and the need for organisational learning (OL) for enhancing sustainability, a literature gap exists in how the concepts of learning organisation and sustainability may be combined in a constructive manner to understand the modes of learning sustainability. The focus of this study is sustainable OL in sustainable companies, and the objective is to understand how companies learn to become sustainable.

To understand how sustainability practices could be assimilated in an organisational environment, this study focuses on the integral cycle of learning (Edwards, 2005, 2009). The study's framework attempts to review past literature, which examines OL dimensions. This paper contributes to previous research on OL characteristics and learning sustainability (Haugh and Talwar, 2010; Wilson and Beard, 2014) and adds to knowledge in the field by approaching sustainability as a systematic business process (Jamali, 2006). The study's analytical framework can be applied to analyse a company's sustainability practices. For this reason, it was required that case companies have sustainability certifications. This helps investigate the OL characteristics in environments that are ready to cultivate and stimulate sustainability practices.

The structure of the paper is as follows. Firstly, an in-depth analysis of the literature is attempted to the compile a list of OL characteristics, such as openness to new ideas and participative policymaking, and they are grouped them into three dimensions: learning orientation; learning process; and learning leadership. Then, a multiple-case study was designed with three sustainability certified companies operating in the food and beverage industry. For each case study, all practices related to sustainability were analysed and mapped according to the framework. Suggestions for future research and possible business implications conclude the paper.

\section{Literature review}

To address the aim of this study, a literature review was conducted in the field of OL to identify how companies learn sustainability. Firstly, sustainability is discussed within the OL perspective. Secondly, OL and the learning dimensions are specified. Thirdly, the analytical framework, based on the present knowledge of the topic, is presented. It lists the OL characteristics that occur within each learning dimension.

\section{Organisational learning and sustainability}

The literature on how companies learn sustainability deals with both OL and sustainability (Haugh and Talwar, 2010; Wilson and Beard, 2014). It propounds that organisations tend to adopt a shortterm focus and act expediently in terms of decision-making (Smith and Sharicz, 2011). However, it can be argued that effective learning for sustainability lies in OL characteristics, such as employee participation, the learning climate, systematic employee development, constant experimentation and learning reward systems (Jamali and Sidani, 2008). Sustainability has, thus, been attained by changing internal processes, OL and employee mindsets (Pourdehnad and Smith, 2012). For instance, customisation can lead to a sustainable process and product innovation through OL (Vos et al, 2018). Specific training and development tools could be used to learn about sustainability, such as codes of conduct, impact measures, company visits and employee volunteering opportunities (Haugh and Talwar, 2010). If integrated into a systematic business process (Jamali, 2006), OL dimensions lead to consolidated sustainability learning. Nonetheless, as acknowledged by Wilson and Beard (2014), among others, academic research requires further investigation to understand how learning and sustainability practices function in companies. Although the literature indicates that sustainability 
learning could be facilitated by several practices, it is not known whether companies develop specific types of learning or cultivate multiple OL dimensions. To help close the gap, this study outlines an analytical framework, based on past literature on OL dimensions.

\section{Organisational learning and learning dimensions}

$\mathrm{OL}$ is one of a number of approaches to learning organisation. As acknowledged by Örtenblad (2018), past studies have struggled to find a common definition of learning organisation, leading to the co-existence of at least four of these: learning at work; climate for learning; OL; and learning structure. With such a multifaceted concept, the organisation may be categorised as a facilitator, a learning unit or the ends to the learning process (Örtenblad, 2018). For this reason, some authors have adopted an overlapping definition (Senge, 1990; Pedler et al., 1991; Watkins and Marsick, 1997). For the purpose of this study, the authors adhere to the idea of the organisation as a learning unit, and thus to the concept of OL (Örtenblad, 2018). This is defined "as a change in the organisation's knowledge that occurs as a function of experience" (Argote, 2011, p. 440).

Following studies in experiential learning (Kolb, 1984; Mainemelis et al., 2002), the learning process is defined as "a cycle of active physical engagement, conceptual reflection, cultural interpretation and social validation that, through multiple iterations, can result in knowledge and insight in individuals and social collectives" (Edwards, 2009, p. 196). Edward's model, called the "integral cycle of learning", operates within two dimensions: individual vs relational; and abstract vs concrete experience. Consequently, four types of learning occur, each characterised by different learning skills: reflective, behavioural, social and cultural learning. Table 1 illustrates these dimensions.

The typology classifies and thus explains learning through sets of dichotomous learning skills. However, academics have not yet successfully applied such typology to the concept of OL in business practices. A framework of such an analysis of OL dimensions and characteristics is presented in the following section.

\section{Analytical framework}

Over the past 20 years, several authors have investigated OL dimensions in companies (Watkins and Marsick, 1997; Moilanen, 2001, 2005; Garvin et al., 2008; Zhou et al., 2015). They tended to collect and compare selected papers based on their own categorisation of learning dimensions. Given the fragmentation of what is already known on the topic, the objective of the literature review was to establish a single framework based on multiple past studies and provide a richer analysis. This is illustrated in Table 2. It classified OL characteristics in three dimensions: learning orientation; learning processes; and learning leadership. For each dimension, several sub-dimensions were identified, with each subdimension explained in depth in the text below. Complete reference lists throughout the text are cited in Table 2.

\begin{tabular}{lll}
\hline Learning types & Learning dimensions & Learning skills \\
\hline Reflective learning & Individual - abstract experience & Observation and reflection \\
Behavioural learning & Individual - concrete experience & Active physical involvement \\
Social learning & Relational - concrete experience & Testing and validating \\
Cultural learning & Relational - abstract experience & Sense-meaning/making
\end{tabular}

Source: adaptation from Edwards (2009)
Sustainable companies 


\begin{tabular}{lll}
\hline Dimensions & Sub-dimensions & Characteristics \\
\hline $\begin{array}{l}\text { Learning } \\
\text { orientation }\end{array}$ & Learning orientation - & Learning culture \\
& contextual & Learning approach to \\
& $\begin{array}{l}\text { Learning orientation }- \\
\text { strategy }\end{array}$ \\
& Openness to new ideas
\end{tabular}

Appreciation of differences

Time for reflection

Presence of creative tension

Psychological safety

Learning orientation collective/relational

Promotion of dialogue and inquiry

Empower of team orientation and collective vision

Learning Learning processes - selfprocesses development (individualfocused)

Reward flexibility

Learning processes - internal structure (structure-focused)
Experimentation

Enabling flexible structure

Formative accounting control

Information collection

Enabling information sharing systems
References

Jamali (2006), Wilson and Beard (2014)

Moilanen (2001, 2005), Jamali (2006), Wilson and Beard (2014) Damanpour (1991), Sinkula et al. (1997), Verona (1999), Moilanen (2001, 2005), Akgun et al. (2007), Garvin et al. (2008), Zhou et al. (2015)

Garvin et al. (2008)

Garvin et al. (2008)

Jamali (2006)

Baer and Frese (2003), Garvin et al. (2008) Zhou et al. (2015) Marsick and Watkins (2003), Yang et al. (2004), Garvin et al. (2008), Wilson and Beard (2014), Tortorella et al. (2015)

Garvin (1993), McGill and Slocum (1993), Hult et al. (2003), Marsick and Watkins (2003),

Yang et al. (2004), Jamali (2006), Tortorella et al. (2015), Zhou et al. (2015)

Continuous training and Marsick and Watkins (2003), Yang et al. (2004), Bryan (2006), Jamali (2006), Hansson (2007), Garvin et al. (2008), Wilson and Beard (2014), Tortorella et al. (2015), Zhou et al. (2015)

Wilson and Beard (2014) Hedberg (1981), Pedler et al. (1989), Senge (1990), LeonardBarton (1992), Garvin (1993), Naman and Slevin (1993), Slocum et al. (1994), Goh (2001), Moilanen (2001, 2005), Jamali (2006), Garvin et al. (2008), Zhou et al. (2015)

Wilson and Beard (2014)

Jamali (2006), Wilson and Beard (2014)

Day (1994), Slater and Narver (1995), Zahra and George (2002), Garvin et al. (2008), Zhou et al. (2015)

Huber (1991), Walsh and Ungson (1991), Simon (1991), Marsick and Watkins (2003), Yang et al. 


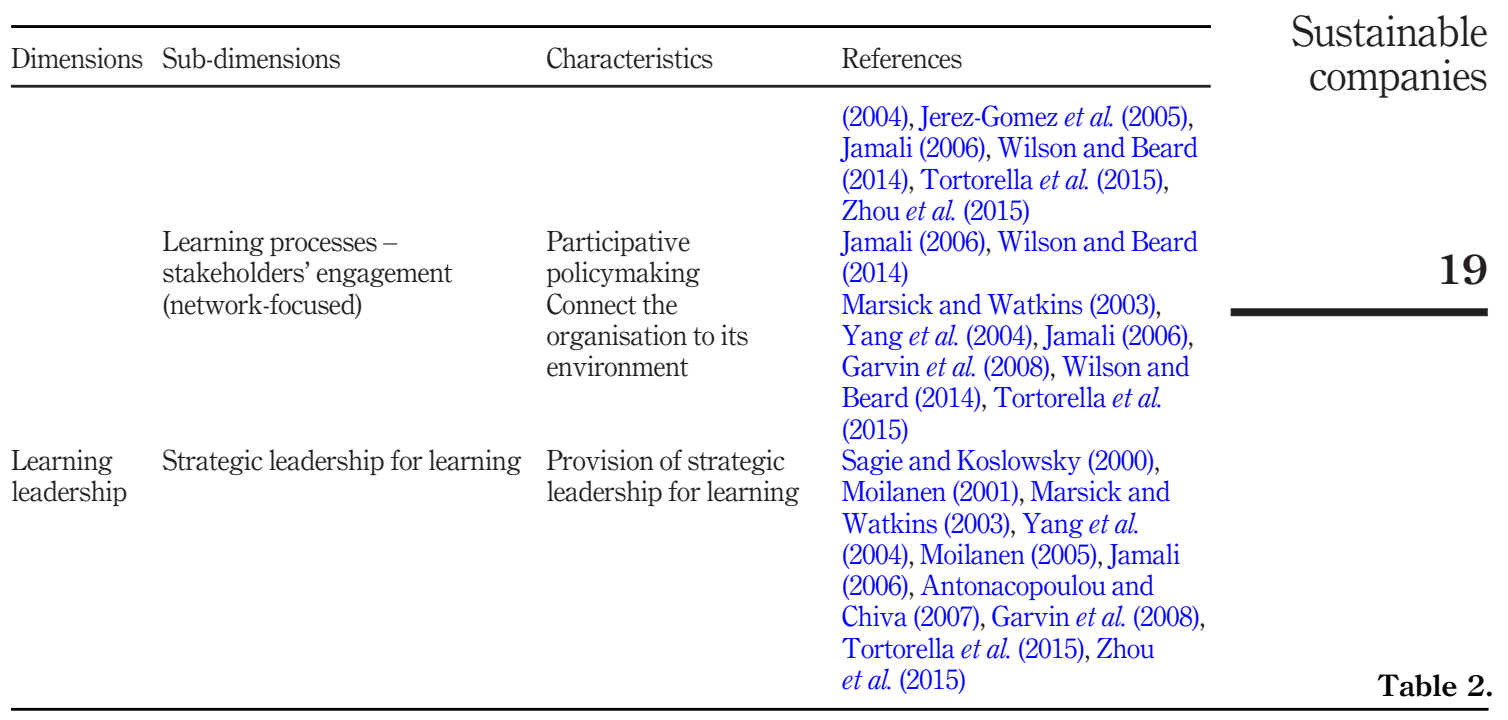

\section{Dimension 1 - learning orientation}

Learning orientation includes all the characteristics that foster the build-up of a supportive learning environment. These characteristics, which have been identified in previous studies, are grouped according to the level of support at which they operate: contextual; individual; or relational.

Moilanen (2001, 2005), Jamali (2006) and Wilson and Beard (2014) describe the contextual level, as that which establishes a learning culture (providing the values behind openness, experimentation, improvisation and continuous learning) and a learning approach to strategy (to develop knowledge to support business strategy).

Learning orientation can also refer to the individual level, which involves characteristics such as openness to new ideas and appreciation of differences (Damanpour, 1991; Verona, 1999; Akgun et al., 2007), in which both novelty and different opinions are valued. This is directly connected to psychological safety (Baer and Frese, 2003; Zhou et al., 2015), that is, the organisational characteristic with which employees feel free to make mistakes, ask for explanations and talk about problems. Another feature of learning orientation at the individual level entails both the presence of creative tension (Jamali, 2006) and time for reflection (Garvin et al., 2008), which refers to the time for reviewing work and avoiding the stress of overwork.

Finally, learning orientation entails a collective and relational sub-dimension in the form of the promotion of dialogue and inquiry (Yang et al., 2004; Tortorella et al., 2015), as well as the empowerment of team orientation and collective vision (Garvin, 1993; McGill and Slocum, 1993; Hult et al., 2003), which foster the exchange of ideas and views among individuals and help create the joint vision of a collaborative work place.

\section{Dimension 2 - learning processes}

Learning processes group OL characteristics according to the focus of concrete business practices: individual; structural; or network. In the first sub-dimension, learning processes focus on individual self-development through initiatives of continuous training and 
TLO

28,1

development, a concept that is referred to by several studies of the framework previously in this paper (Bryan, 2006; Hansson, 2007). This feature considers the provision of resources and facilities, encouraging the self-development of employees and could be accompanied by reward flexibility, such that employees are rewarded for providing new ideas (Wilson and Beard, 2014).

Learning processes, however, are mainly driven by a focus on the internal structure of the organisation and take diverse forms. Two examples are the systematic collection of information (Day, 1994; Slater and Narver, 1995; Zahra and George, 2002) and formative accounting control (Jamali, 2006; Wilson and Beard, 2014), both of which are designed to aid learning and decision-making. The adoption of such information sharing systems with the support of technology is instrumental in enhancing the processes of learning within the organisation (Huber, 1991; Simon, 1991; Jerez-Gomez et al., 2005). Other characteristics include experimentation (Hedberg, 1981; Leonard-Barton, 1992; Goh, 2001), which entails processes of creativity and generative learning and the adoption of a flexible structure for the business organisation (Wilson and Beard, 2014).

The third focus of learning processes is the network, which refers to stakeholders' engagement. Examples include, participatory policymaking, which involves all stakeholders (Jamali, 2006; Wilson and Beard, 2014), or establishing a connection between the organisation and its environment, to make organisational boundaries permeable and enable learning from customers, suppliers, competitors and the local community in general (Yang et al., 2004; Garvin et al., 2008).

\section{Dimension 3 - learning leadership}

Researchers have unanimously recognised the relevance of leadership support in stimulating OL (Sagie and Koslowsky, 2000; Antonacopoulou and Chiva, 2007). Strategic leadership for learning is a major dimension, which provides support for learning orientation and learning processes in reinforcing and encouraging the previously discussed dimensions. It follows that the role of managers and directors is critical in providing conditions for enabling OL.

\section{Methods}

The following section on the methodology, outlines how the research was designed (Research design), how the sample was selected (Sample), and how the data was collected (Data collection) and analysed (Data analysis).

\section{Research design}

The research attempts to expand knowledge on sustainable companies in terms of the above-mentioned OL characteristics. A multiple-case study approach was considered suitable for this study, for the very reason that it sets out to describe how sustainable companies adopt OL characteristics in incorporating sustainability. Such a methodology is descriptive, explanatory and exploratory (Yin, 1993; Wilson and Beard, 2014). Although other studies, such as that of Wilson and Beard (2014), used a single case study (i.e. Marks and Spencer) to outline the characteristics of a sustainable learning organisation, a multiplecase study approach is not uncommon such studies.

\section{Sample}

The case companies were chosen based on their fitness, distinctiveness and revelatory nature (Siggelkow, 2007; Yin, 2003). Specifically, three case studies (see "Description of the case studies") that have sustainability certifications were selected to investigate the OL 
characteristics in environments that are ready to cultivate and stimulate sustainability practices. The companies belong to the food and beverage sector, the second most active Italian sector in the adoption of sustainability practices and adherence to the United Nations Global Compact Initiative. Within the group of sample companies, team leaders in charge of corporate social responsibility (CSR) were interviewed, as they were aware of sustainability practices in the companies.

Data collection

Data collection took place throughout 2017 and used both primary and secondary sources. The primary sources of information comprised three interviews with managers of the case companies. Each interview lasted approximately $2 \mathrm{~h}$ each (one-time events). One of the researchers conducted and recorded the interviews, which were structured in three parts: the first was general in scope (e.g. "Could you sum up the main facts of your company?"; "What are your main strategies?"). The second was concerned with OL (e.g. "Do you deliver any actions to prompt learning in the company?"). The third was concerned with sustainability (e.g. "What are the main sustainability practices in the company?"; "How is sustainability achieved in the company?").

The secondary sources were case companies' materials, such as their business reports, sustainability reports, ethical codes, company websites and press releases. Useful information was judged to be that dealing with adopted sustainability practices. This was done to verify whether actions taken by the examined companies complement the managers' statements during the interviews.

\section{Data analysis}

The data analysis was based on both interview transcripts and secondary sources. The analysis adopted thematic coding of the collected information (Gibbs, 2007) with reference to the framework of analysis shown in Table 2. That is to say, the sustainability practices were analysed in terms of recognised OL dimensions and characteristics. Each practice was matched with one or more OL characteristics to position the practice within the OL characteristics framework. The ordering of the OL dimensions was also used to guide the description of the findings.

\section{Case studies}

Case $\mathrm{A}$ is a joint-stock company that conducts manufacturing, bottling, importing and sale of beer. The company evaluates the environmental impact of its product with the life cycle assessment (LCA) tool. This company integrates environmental and social sustainability into its business. Despite being new in many aspects, the strategy is based on the concept of "contributing to a better society" to make beer production a more sustainable process. It is based on the belief that economic activities must promote approaches like circular economy to improve production practices. The company has chosen to report priorities following the beer life cycle: water, energy and emissions (production process); health and safety (particularly of the people who produce and market beer); and responsible consumption (respect for consumers).

Case B produces high-quality coffee, which is marketed across the world. Case B places the creation of shared value for stakeholders at the centre of its work and believes in the two fundamental values of excellence and ethics. It considers sustainability to be at the very heart of its mission. This case seeks to achieve the needs of the present without compromising the possibility for future generations to satisfy their own needs. The company objectives are economic (pursuing economic 
TLO

28,1

sustainability through the concept of shared value creation with stakeholders); environmental (pursuing environmental sustainability through the concept of respect, which translates into the principles of not polluting, not wasting and using renewable resources); and social (pursuing social sustainability through the concept of growth, knowledge-creation and self-realisation).

Case $\mathrm{C}$ currently has the largest presence in the beverage industry in Italy and is one of the leading companies internationally. It conducts its activities in a coherent and synergistic way to achieve the ultimate goals of the company: improving the quality of life and contributing to creating a healthier future. The company contributes to the creation and support of the 17 sustainable development goals defined by the United Nations. This case carries on various activities in the field of sustainability, such as the daily monitoring of the sources and the surrounding ecosystem and the promotion of educational activities on the correct use of water. Taking care, of water resources, for Case $\mathrm{C}$, means not only protecting the surrounding ecosystems but also building an open dialogue with its reference public to disseminate information on this resource.

\section{Findings and discussion}

The literature review provides a framework for OL characteristics (Table 2). As the aim of this study is to understand sustainable OL in sustainable companies, sustainability practices of each case study have been analysed and mapped according to the framework and its dimensions (i.e. learning orientation, learning processes and learning leadership). Table 3 collects the practices, which are described in the text below. In this way, the analysis furthers our understanding of how OL occurs.

\section{Sustainability practices in learning orientation}

The case studies develop sustainability practices at the contextual level, promoting both a learning culture and a learning approach to strategy with specific reference to environmental-related issues. Nonetheless, each case approaches sustainability practices differently at both individual and collective levels. Case A ignores initiatives at an individual level entirely, whereas Cases B and C apply them infrequently at best; initiatives for innovation and talent reward are prevalent.

In addition, there are few examples of a collective learning orientation through the promotion of dialogue, inquiry or empowerment of teams and collective vision. The few examples include the formalisation of exchange moments among employees and programs to foster their sense of belonging to the company. Case $\mathrm{C}$ organises a hackathon for developing innovative solutions and boosting team building. Case A seeks to promote dialogue between the organisation and the employees through internal communication systems, which are also useful for reporting safety issues. In conclusion, the results show that, although a great deal of importance is given to practices related to a contextual learning orientation, there are few initiatives at an individual and collective learning level.

\section{Sustainability practices in learning processes}

Most of the examined sustainability practices pertain to learning processes and focus mainly on internal structure and networking. Practices of self-development are mostly connected to training for both professional development and environmental and safety issues. Examples of observed practices for employee self-development and training include engagement of a development planner and the application of a 


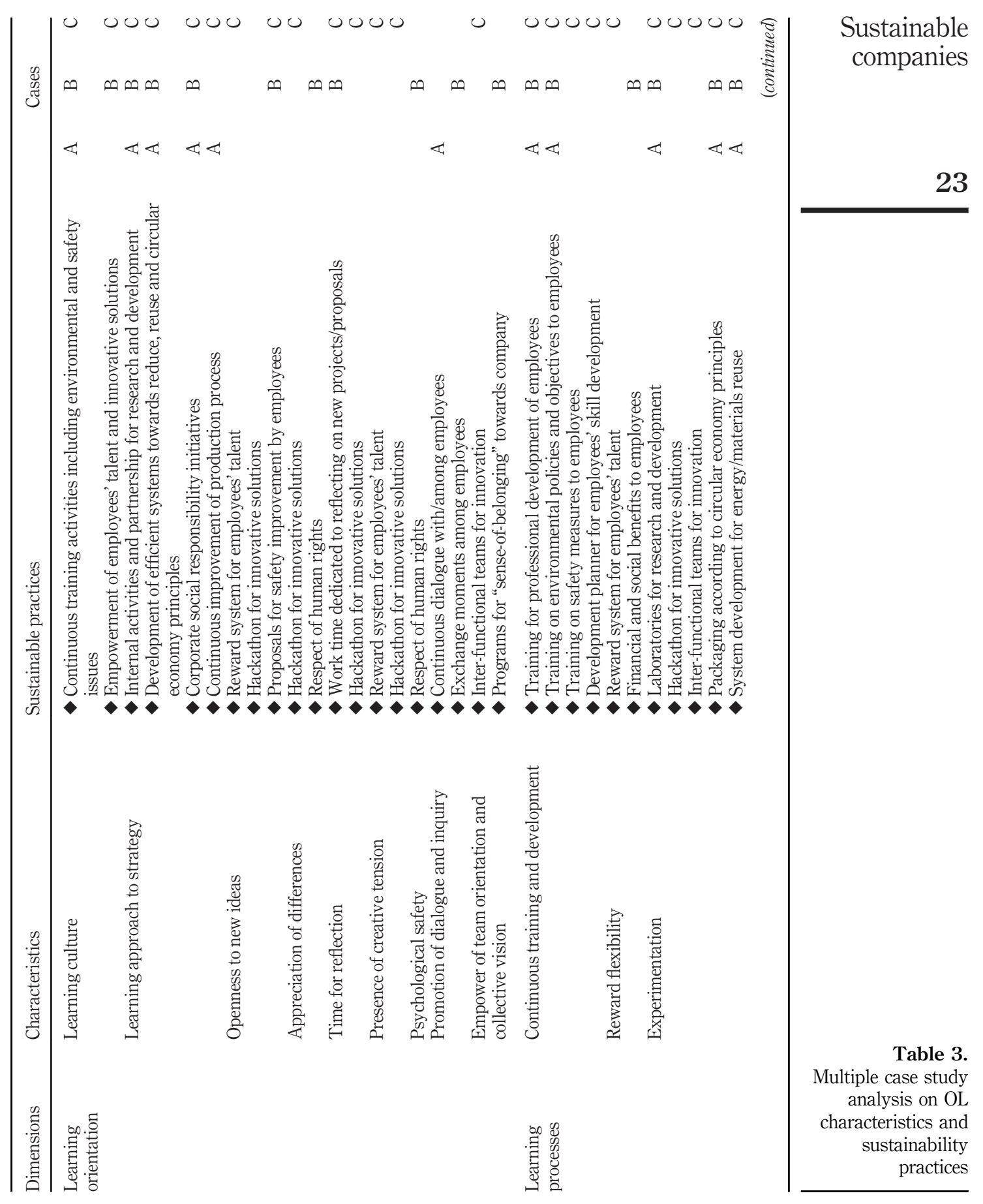




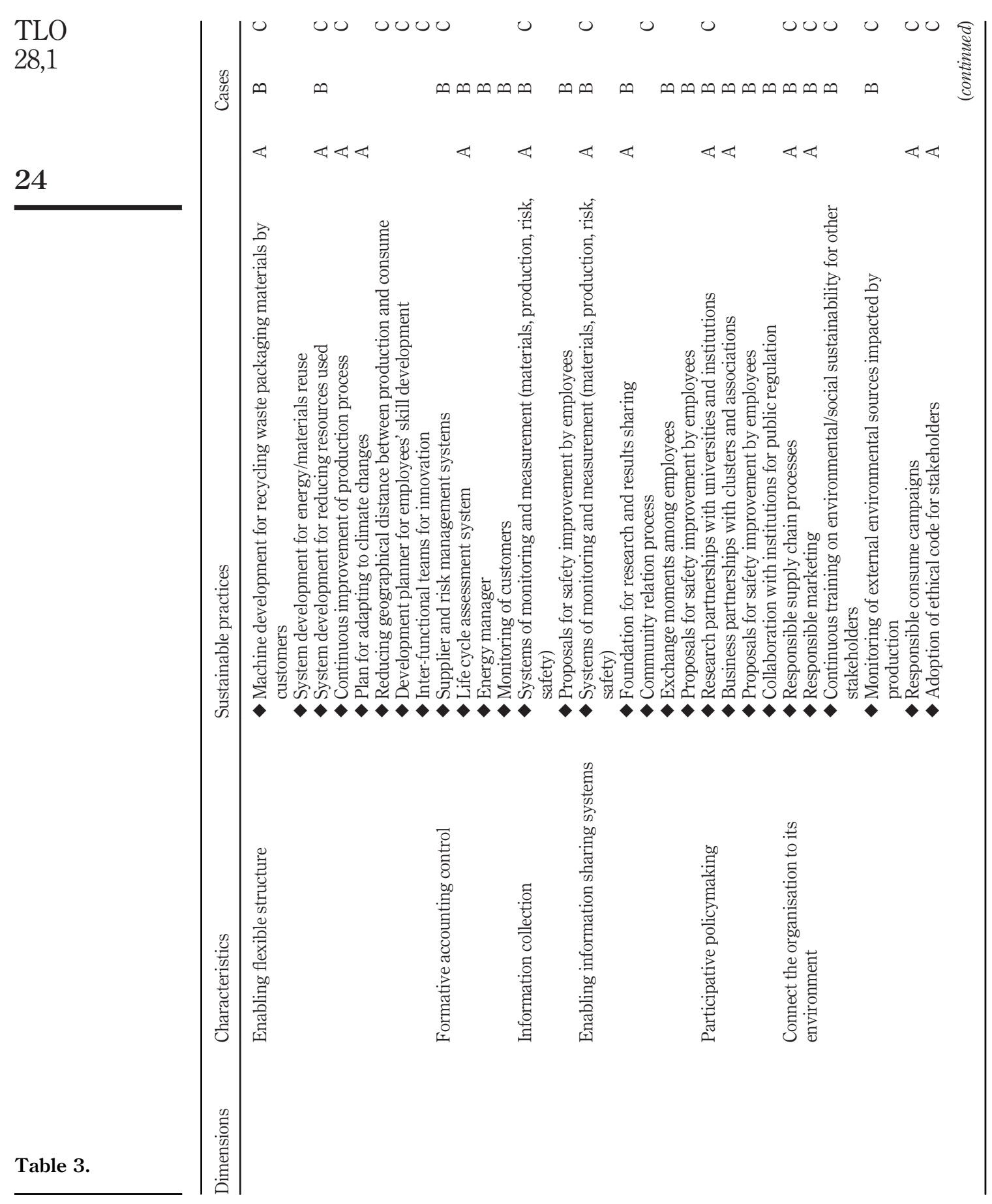




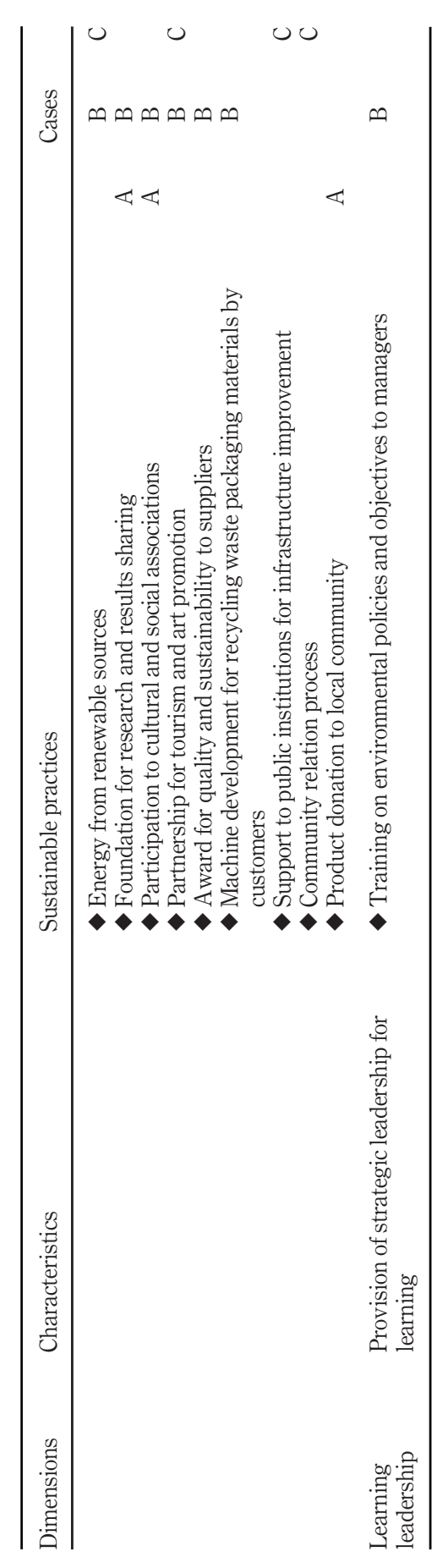

Sustainable companies

25

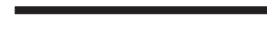

Table 3. 
TLO

28,1

70:20:10 learning and development model. The 70:20:10 formula represents 70\% challenging assignments (learning by doing), 20\% developmental relationships (learning by networking) and 10\% courses (learning by training) (Rabin, 2014). From the environmental sustainability perspective, Case $\mathrm{C}$ organises training courses for truck drivers on safe and less-polluting driving. Value is given to human resources through training with specific corporate training schools. However, there are few examples of social sustainability related to rewarding employees, and it is done using financial and social benefits.

Many sustainability activities focus on experimentation. This includes research and development activities with a specific interest in circular economy principles and the development of systems to reuse and recycle. Although all the experimentation practices take diverse forms, the label of "system development for energy/materials reuse" includes internal structure practices such as the acquisition of only renewable energy sources, the switch to paperless offices, weight-reduction systems, heat and water reuse systems and less-polluting machinery. Examples of experimentation can also be viewed from a consumer perspective. This includes the creation of packages using organic materials in Cases $\mathrm{A}$ and $\mathrm{C}$ and the development of less-polluting products in case A. All the cases practise sustainability by applying flexible structures in resource usage and in continuous improvement of the production process.

All the cases formalise and structure analysis systems via formative accounting control, such as supplier and risk management systems and/or LCA, use systems of monitoring and measurement of materials, production, risk, safety and enhancement of information collection and sharing. In Case A, this sub-dimension also includes the formalisation of sharing systems with/among employees. Examples of information-sharing systems are supplier management systems, sourcing risk management systems and environmental management systems.

Finally, stakeholder engagement takes several forms in each case study. Participative policymaking is rather rare when compared to the establishing a connection between the company and its environment. Indeed, in Case A, it is limited to research partnerships with universities and research institutions. However, ethical concerns appear to be well established and diverse in all cases. Case $\mathrm{C}$ relies on responsible and ethical practices mostly by applying an ethical code of stakeholders. In the other cases, practices are addressed to environmental sustainability through the training of stakeholders, monitoring of company impact and the use of renewable energy sources. Additional references are connected to the involvement of institutions and the community in their sustainability practices, rather than a focus on production and suppliers. In conclusion, the common point of interest in stakeholder engagement appears to be connected CSR, especially with regard to marketing and the supply chain. On the one hand, suppliers are selected and even awarded according to quality and sustainability criteria; on the other, consumers are trained and monitored through sustainability campaigns.

\section{Sustainability practices in learning leadership}

From the analysis of the case studies, only Case B specifically involves managers, that is, only Case B trains managers in environmental policies and objectives. Interestingly, no other practices entail any distinction between employees and managers, and there is an absence of any other reference to leadership roles to support sustainability. 
Final overview and discussion

With reference to Edwards (2009) framework, several differences emerge from the case studies. Even though the three companies have similar businesses, they adopt and develop sustainability in diverse modes and with different subjects, tools and purposes.

Case A mainly builds its sustainability practices on social learning, with most of its initiatives focussing on concrete and relational experiences. For instance, the company has adopted a system for reducing the resources used and reusing energy and materials. It also encourages cultural learning in its sustainability practices, as in the case of its ethical code for stakeholders but does not show much interest in fostering either reflective or behavioural learning.

Case B implements all types of learning covered in Edwards (2009) typology. The company develops sustainability practices in reflective, behavioural, social and cultural learning, showing both individual and relational as well as both abstract and concrete practices. For instance, the empowerment of employees' talent contributes to enhancing reflective learning, while proposals for safety improvement by employees reflect an individual and concrete learning mode and thus indicates behavioural learning.

Case $\mathrm{C}$ shows an extended range of learning types (behavioural, social and cultural) in its sustainability practices. The presence of inter-functional teams for innovation implies a social learning mode, where relational and concrete actions are characteristics of the teams' activity. The presence of a development planner for employees' skill development is indeed an example of an individual and concrete experience, which is related to behavioural learning.

In conclusion, sustainability practices are well-developed by all case studies through social learning, especially in their adoption of concrete and relational experiences. In addition, cultural and behavioural learning are widely diffused. Less development, however, is evidenced in reflective learning within sustainability practices. Thus, understanding how sustainable companies learn sustainability reveals not only how different modes occur but also how specific OL dimensions are supported by certain practices.

\section{Conclusions and implications}

The purpose of this study is to expand the knowledge on sustainable OL in sustainable companies. Though its analytical framework of learning dimensions and the case studies of certified sustainable companies, this study outlines the ways in which the concepts of OL and sustainability intersect in the real business world. The case studies mainly focus on learning processes and social learning. Although the diffusion of sustainability practices is evident in all the companies, their approaches to learning differ according to their respective business experiences. Reflective learning is, for instance, seen in all cases as rather undeveloped.

It is often argued that organisations focus mainly on short-term results (Smith and Sharicz, 2011). However, following the recommendation of Smith and Sharicz (2011), this research has embraced a long-term and comprehensive view, that values of shared leadership, self-managed teams and learning should be instilled in an organisation. This study contributes to broadening Jamali's (2006) view that solid OL dimensions guarantee a more adequate means to face sustainability challenges and provide insight into implementing a practical application of sustainability in the OL context, as called for in Haugh and Talwar (2010) and Wilson and Beard (2014).
Sustainable companies 
TLO

28,1

This study was descriptive in aim and, as such, is subject to some limitations. Firstly, the use of case study methodology, by its very nature, limits the possible generalisations of the results and produces context-dependent knowledge. Secondly, the framework could have drawn from different past research than the ones proposed here. Thirdly, companies may concretely develop additional sustainable initiatives without specifically intending to. Reporting sustainable initiatives, for instance, could exclude some routines and unstructured processes of the company.

To overcome such limitations, a future research agenda should contemplate the use of mixed methods that will deepen the development of sustainability practices from the OL perspective. In such a way, it is possible to extend the understanding of the preliminary results presented in this study. Moreover, the theoretical framework could further develop and encompass specific organisational characteristics for sustainability. Finally, a key research objective could address the lack of structured development in strategic leadership in the learning of sustainability practices.

This study provides a systematic collection of sustainability practices within a theoretical framework in OL. It thus contributes to the field of knowledge on OL by analysing sustainability in three case studies. This allows us to examine how sustainable companies have incorporated sustainability and helps us jointly address OL and sustainability.

Implications for practice and policies may address initiatives to support reflective learning, which appears to be the least developed facet among the companies. Practical implications target organisational self-assessment through both the framework of analysis and the collection of actual examples by sustainable companies.

In conclusion, this study is one of a few that explore sustainable learning in companies and contributes to recognising and categorising the OL characteristics of companies that facilitate sustainability in the mid- to long-term period.

\section{References}

Akgun, A.E., Keskin, H., Byrne, J.C. and Aren, S. (2007), "Emotional and learning capability and their impact on product innovativeness and firm performance", Technovation, Vol. 27 No. 9, pp. 501-513.

Antonacopoulou, E. and Chiva, R. (2007), "The social complexity of organizational learning: the dynamics of learning and organizing", Management Learning, Vol. 38 No. 3, pp. 277-295.

Argote, L. (2011), "Organizational learning research: past, present and future”, Management Learning, Vol. 42 No. 4, pp. 439-446.

Baer, M. and Frese, M. (2003), "Innovation is not enough: climates for initiative and psychological safety, process innovations, and firm performance", Journal of Organizational Behavior, Vol. 24 No. 1, pp. 45-68.

Bryan, J. (2006), "Training and performance in small firms", International Small Business Journal: Researching Entrepreneurship, Vol. 24 No. 6, pp. 635-660.

Damanpour, F. (1991), "Organizational innovation: a meta-analysis of effects of determinants and moderators", Academy of Management Journal, Vol. 34 No. 3, pp. 555-590.

Day, G. (1994), "Continuous learning about markets”, California Management Review, Vol. 36 No. 4, pp. 9-31.

Edwards, M.G. (2005), "The integral holon: a holonomic approach to organisational change and transformation", Journal of Organizational Change Management, Vol. 18 No. 3, pp. 269-288.

Edwards, M.G. (2009), "An integrative metatheory for organisational learning and sustainability in turbulent times", The Learning Organization, Vol. 16 No. 3, pp. 189-207. 
Garvin, D. (1993), “Building a learning organization”, Harvard Business Review, Vol. 71 No. 4, pp. 78-91.

Garvin, D.A., Edmondson, A.C. and Gino, F. (2008), "Is yours a learning organization?", Harvard Business Review, Vol. 86 No. 3, pp. 109-116.

Gibbs, G.R. (2007), “Thematic coding and categorizing”, Analysing Qualitative Data, Vol. 703, pp. 38-55.

Goh, S.C. (2001), "The learning organization: an empirical test of a normative perspective", International Journal of Organizational Theory and Behaviour, Vol. 4 No. 1, pp. 329-355.

Hansson, B. (2007), "Company-based determinants of training and the impact of training on company performance", Personnel Review, Vol. 36 No. 2, pp. 311-331.

Haugh, H.M. and Talwar, A. (2010), "How do corporations embed sustainability across the organization?", Academy of Management Learning and Education, Vol. 9 No. 3, pp. 384-396.

Hedberg, R. (1981), How Organizations Learn and Unlearn, Handbook of Organizational Design, Oxford University Press, Oxford.

Huber, G.P. (1991), “Organizational learning: the contributing processes and the literatures", Organization Science, Vol. 2 No. 1, pp. 88-115.

Hult, G.T.M., Ketchen, D.J. and Nichols, E.L. (2003), "Organizational learning as a strategic resource in supply management", Journal of Operations Management, Vol. 21 No. 5, pp. 541-556.

Jamali, D. (2006), "Insights into triple bottom line integration from a learning organization perspective", Business Process Management Journal, Vol. 12 No. 6, pp. 809-821.

Jamali, D. and Sidani, Y. (2008), "Learning organizations: diagnosis and measurement in a developing country context: the case of Lebanon", The Learning Organization, Vol. 15 No. 1, pp. 58-74.

Jansson, J., Nilsson, J., Modig, F. and Hed Vall, G. (2017), "Commitment to sustainability in small and medium-sized enterprises: the influence of strategic orientations and management values", Business Strategy and the Environment, Vol. 26 No. 1, pp. 69-83.

Jerez-Gomez, P., Cespedes-Lorente, J. and Valle-Cabrera, R. (2005), "Organizational learning capability: a proposal of measurement”, Journal of Business Research, Vol. 58 No. 6, pp. 715-725.

Johnson, M.P. and Schaltegger, S. (2016), "Two decades of sustainability management tools for SMEs: how far have we come?", Journal of Small Business Management, Vol. 54 No. 2, pp. 481-505.

Kolb, D.A. (1984), Experiential Learning: Experience as the Source of Learning and Development, Prentice Hall, Englewood Cliffs, NJ.

Leonard-Barton, D.A. (1992), "The factory as a learning laboratory", MIT Sloan Management Review, Vol. 34 No. 1, pp. 23-28.

McGill, M.E. and Slocum, J.W. (1993), “Unlearning the organization”, Organizational Dynamics, Vol. 22 No. 2, pp. 67-79.

Mainemelis, C., Boyatzis, R.E. and Kolb, D.A. (2002), "Learning styles and adaptive flexibility: testing experiential learning theory”, Management Learning, Vol. 33 No. 1, pp. 5-33.

Marsick, V.J. and Watkins, K.E. (2003), "Demonstrating the value of an organization's learning culture: the dimensions of the learning organization questionnaire", Advances in Developing Human Resources, Vol. 5 No. 2, pp. 132-151.

Moilanen, R. (2001), "Diagnostic tools for learning organizations", The Learning Organization, Vol. 8 No. 1, pp. 6-20.

Moilanen, R. (2005), "Diagnosing and measuring learning organizations", The Learning Organization, Vol. 12 No. 1, pp. 71-89. 
Naman, J.L. and Slevin, D.P. (1993), "Entrepreneurship and the concept of fit: a model and empirical tests", Strategic Management Journal, Vol. 14 No. 2, pp. 137-153.

Örtenblad, A. (2018), “What does ‘learning organization’ mean?”, The Learning Organization, Vol. 25 No. 3, pp. 150-158.

Pedler, M., Boydell, T. and Burgoyne, J. (1989), "Towards the learning company", Management Education and Development, Vol. 20 No. 1, pp. 1-8.

Pedler, M., Burgoyne, J. and Boydell, T. (1991), The Learning Company: A Strategy for Sustainable Development, McGraw-Hill, London.

Pourdehnad, J. and Smith, P.A. (2012), "Sustainability, organizational learning, and lessons learned from aviation", The Learning Organization, Vol. 19 No. 1, pp. 77-86.

Rabin, R. (2014), "Blended learning for leadership: the CCL approach”, Center for Creative Leadership, available at: www.ccl.org/wp-content/uploads/2015/04/BlendedLearningLeadership.pdf

Ritala, P., Huotari, P., Bocken, N., Albareda, L. and Puumalainen, K. (2018), "Sustainable business model adoption among S\&P 500 firms: a longitudinal content analysis study", Journal of Cleaner Production, Vol. 170, pp. 216-226.

Sagie, A. and Koslowsky, M. (2000), Participation and Empowerment in Organizations: Modeling, Effectiveness, and Applications, Sage, Thousand Oaks, CA.

Senge, P. (1990), The Fifth Discipline: Art and Practice of the Learning Organization, Doubleday, New York, NY.

Siggelkow, N. (2007), "Persuasion with case studies", Academy of Management Joumal, Vol. 50 No. 1, pp. 20-24.

Simon, H.A. (1991), "Bounded rationality and organizational learning", Organization Science, Vol. 2 No. 1, pp. 125-134.

Sinkula, J.M., Baker, W.E. and Noordewier, T. (1997), "A framework for market-based organizational learning: linking values, knowledge, and behavior", Journal of the Academy of Marketing Science, Vol. 25 No. 4, pp. 305-318.

Slater, S.F. and Narver, J.C. (1995), "Market orientation and the learning organization", Journal of Marketing, Vol. 59 No. 3, pp. 63-74.

Slocum, J.W., McGill, M. and Lei, D.T. (1994), "The new learning strategy: anytime, anything, anywhere", Organizational Dynamics, Vol. 23 No. 2, pp. 33-47.

Smith, P.A.C. and Sharicz, C. (2011), "The shift needed for sustainability", The Learning Organization, Vol. 18 No. 1, pp. 73-86.

Tortorella, G.L., Marodin, G.A., Miorando, R. and Seidel, A. (2015), “The impact of contextual variables on learning organization in firms that are implementing lean: a study in Southern Brazil", The International Journal of Advanced Manufacturing Technology, Vol. 78 Nos 9/12, pp. 1879-1892.

Verona, G. (1999), “A resource-based view of product development”, Academy of Management Review, Vol. 24 No. 1, pp. 132-142.

Vos, M.A., Raassens, N., van der Borgh, M. and Nijssen, E.J. (2018), "Balancing modularity and solution space freedom: effects on organisational learning and sustainable innovation", International Journal of Production Research, Vol. 56 No. 20, pp. 6658-6677.

Walsh, J.P. and Ungson, G.R. (1991), "Organizational memory", Academy of Management Review, Vol. 16 No. 1, pp. 57-91.

Watkins, K.E. and Marsick, V.J. (1997), Dimensions of Learning Organization, Partners for the Learning Organization, Warwick, RI.

Wilson, J.P. and Beard, C. (2014), "Constructing a sustainable learning organization: marks and spencer's first plan a learning store", The Learning Organization, Vol. 21 No. 2, pp. 98-112.

Yang, B., Watkins, K.E. and Marsick, V.J. (2004), "The construct of the learning organization: dimensions, measurement, and validation", Human Resource Development Quarterly, Vol. 15 No. 1, pp. 31-55. 
Yin, R. (1993), Applications of Case Study Research, Sage Publishing, Newbury Park, CA.

Yin, R. (2003), Case Study Research Design and Methods. Applied Social Research Methods, Sage Publishing, Newbury Park, CA.

Zahra, S.A. and George, G. (2002), "Absorptive capacity: a review, reconceptualization, and extension”, Academy of Management Review, Vol. 27 No. 2, pp. 185-203.

Zhou, W., Hu, H. and Shi, X. (2015), "Does organizational learning lead to higher firm performance? An investigation of Chinese listing companies", The Learning Organization, Vol. 22 No. 5, pp. 271-288.

Corresponding author

Cinzia Battistella can be contacted at: cinzia.battistella@uniud.it

For instructions on how to order reprints of this article, please visit our website: www.emeraldgrouppublishing.com/licensing/reprints.htm Or contact us for further details: permissions@emeraldinsight.com 